\title{
Thermal characteristics of novel brake friction materials for light rail transit applications
}

\author{
N. Valliyappan, D. Berhan, M. N. Darius \& G. Solomon \\ Faculty of Mechanical Engineering, Universiti Teknologi MARA (UiTM), \\ Shah Alam, Malaysia
}

\section{Abstract}

A batch of five formulations (SP1, SP2, SP3, SP4 and SP5) of novel brake friction materials are being developed and tested for light rail transit (LRT) applications. This paper presents the thermogravimetric (TG) and derivative thermogravimetric (DTG) analysis coupled with the mass spectroscopy (MS) of those friction material samples. The LRT braking system operates at elevated temperatures and may reach an upper extreme of $900^{\circ} \mathrm{C}$. In this research, temperature range from ambient to $600^{\circ} \mathrm{C}$ is considered the temperature zone that signifies the limits of normal braking operation and considerable weight loss. In general, all samples except SP4, decompose in four steps and registered significant weight loss averaging $5.53 \%( \pm 0.20 \%)$ of the original weight. Sample SP4 experienced the highest weight loss of $5.77 \%$ in three steps. Samples SP1 and SP5 were found to be stable, temperature wise, in decomposing compared to all other samples. Sample SP1 exhibited a controlled rate of decomposition apparently over a wider temperature range $\left(230^{\circ} \mathrm{C}-\right.$ $688^{\circ} \mathrm{C}$ ) with a total loss of weight of $5.37 \%$. In contrast, sample SP5 decomposed in a greater magnitude over a narrower temperature gap $\left(303^{\circ} \mathrm{C}-\right.$ $483^{\circ} \mathrm{C}$ ) albeit the total weight reduction is $5.30 \%$. MS signals indicating mass number of 2 and 44 was detected in all samples at critical temperature zones corresponding to substantial weight loss. This denotes the probable evolution of compounds consisting of hydrogen, helium, carbon dioxide, nitrogen oxide and propane and is related to the physical-chemical reaction which is explained in this paper.

Keywords: thermogravimetric analysis, mass spectroscopy, friction material, light rail transit. 


\section{Introduction}

Friction materials are complex composites comprising steel and ceramic fibres, abrasives, lubricants, metallic and semi-metallic fillers [1]. Friction materials, also generally known as brake pad, should be able to sustain thermal shocks and surface cracks besides other considerations such vibration damping and noise suppression. The friction and wear performance of friction materials is a function of the material composition, microchemical structure of the pad, rotating speed, pressure and contact surface temperature [2-4].

Brake pads are exposed to large thermal stresses during routine braking and may be subjected to unusual thermal load cycles during hard braking. High-g decelerations of passenger trains are known to generate temperatures as high as $900^{\circ} \mathrm{C}$ in a fraction of a second [5]. Brake operating conditions related to heat generation include braking pressure and rubbing velocity. However, in normal operating conditions, braking should cause a temperature increase up to around $500^{\circ} \mathrm{C}$ [6]. Mutlu et al. [7] studied about the tribological changes as a function of temperature up to $400^{\circ} \mathrm{C}$. It is therefore expected that the generation of heat during braking and hence the elevation of temperature could bring about chemical reactions which tend to cause decomposition of constituent materials. Consequently, the chemical constitution of the brake pad continuously varies from its original composition, releasing gases in the process of thermal degradation.

The method of detecting changes in weight as a function of temperature under defined atmospheric conditions is termed thermogravimetric analysis (TG). Derivative thermogravimetric (DTG) is the time rate of reaction derived from the TG results. In view of the possibility of materials discharging gases during the temperature ramp, TGA is usually approached in tandem with evolved gas analysis (EGA) such as mass spectroscopy (MS). The combination of thermal and evolved gas analyses is highly recommended and used extensively in a variety of materials research initiatives [8-10].

This paper presents the TG/DTG-MS coupled analysis of five novel formulations of brake friction materials, which are intended for final usage in the LRT braking system in Malaysia. Characteristic temperatures corresponding to initial weight decomposition and maximum rate of decomposition are highlighted and related to the possible molecule release at those temperatures.

\section{Experimental}

Mettler Toledo TGA/SDTA851e was used for the TG-MS coupled analysis. The mass spectrum of the gaseous products which evolved during heating is obtained by coupling the TG thermobalance on-line to the MS via a heated quartz glass capillary tube. Samples were heated from $30^{\circ} \mathrm{C}$ to $1000^{\circ} \mathrm{C}$ at a scan rate of $10^{\circ} \mathrm{C} / \mathrm{min}$ under flow of $50 \mathrm{ml} / \mathrm{min}$ of nitrogen. The TG/DTG-MS spectra were generated by plotting the continuous change of sample weight and ion intensities (mass-to-charge ratio) of the gaseous products as a function of temperature. 


\section{Results and discussion}

\subsection{TG/DTG of raw materials and commercial brake pad}

There are more than 25 individual compounds in form of fibres and solids used for the preparation of the five new brake pad formulations. This section provides a brief overview of the TG/DTG results for the some of the raw ingredients namely, barium (filler), rubber (organic additive), Nipol (a proprietary polymerbased material) and iron oxide (modifier), which are used to explain the TG-MS results of the samples.

The TG/DTG curves for the commercial brake pad are shown in fig. 1. The material decomposed in two stages beyond $200^{\circ} \mathrm{C}$. The polymeric binder decomposed up to $550^{\circ} \mathrm{C}$ at a rate of below $0.5 \%$ per minute. Total weight loss is $4.79 \%$ up to $680^{\circ} \mathrm{C}$. This marks the reference amount of total weight loss for the five new brake pad formulations.

Fig. 2 shows the TG/DTG thermogram of barium. The sample gained weight to a maximum of $100.07 \%$ at rate of $0.25 \%$ at $180^{\circ} \mathrm{C}$, which could be due to reaction with the surrounding atmosphere. After $380^{\circ} \mathrm{C}$, weight loss was registered in three stages with maximum loss at a rate of $0.15 \%$ at $546.3^{\circ} \mathrm{C}$.

The thermal decomposition pattern for rubber in given by fig. 3. This sample was stable under heating up to $245^{\circ} \mathrm{C}$ but decomposes in one-step until the $550^{\circ} \mathrm{C}$ after which no weight loss was registered.

Fig. 4 shows the TG/DTG results for Nipol (a proprietary polymer-based material) indicating a 3-stage decomposition as the sample is heated. The significant loss of weight is at the second stage for which the temperature bandwidth is between $355^{\circ} \mathrm{C}$ and $535^{\circ} \mathrm{C}$. This sample can decompose at a rate as high as $32 \%$ per minute, hence its chemical reaction to high temperature.

The TG/DTG plot for iron oxide is shown in fig. 5. It is observed that at $49.78^{\circ} \mathrm{C}$ the sample gains weight up to $0.05 \%$, possibly because of further oxidation during initial heating. Similar result was analysed elsewhere [11]. The two-stage decomposition process begins at around $220^{\circ} \mathrm{C}$. The first stage occurred between $221.2^{\circ} \mathrm{C}$ and $345.6^{\circ} \mathrm{C}$. Above this temperature, the sample underwent gradual increment of weight loss (in \%; DTG) up to $0.24 \%$ at $996.3^{\circ} \mathrm{C}$. The curve indicates infinitesimal decomposition slightly above $700^{\circ} \mathrm{C}$.

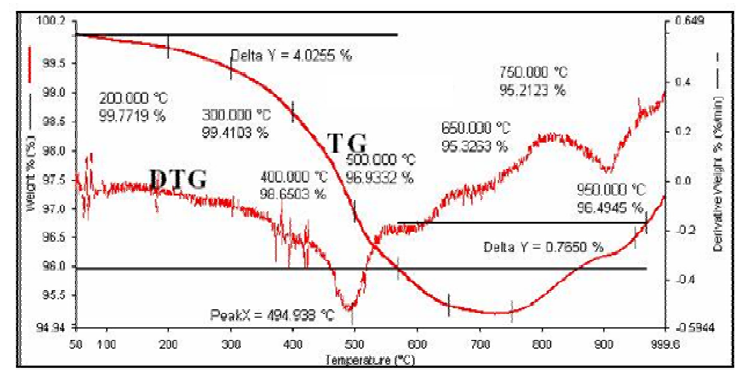

Figure 1: $\quad$ TG/DTG curve of commercial brake pad. 


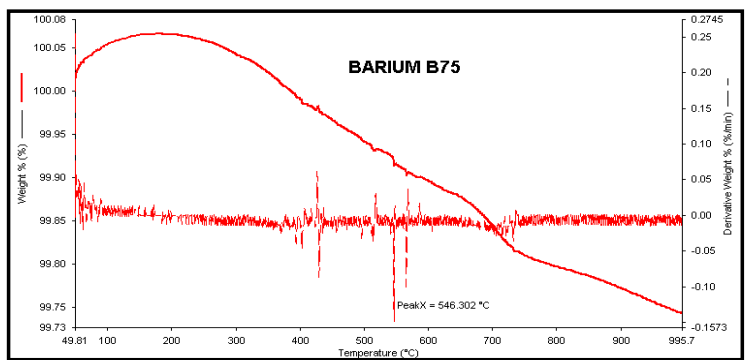

Figure 2: $\quad$ TG/DTG curve of barium.

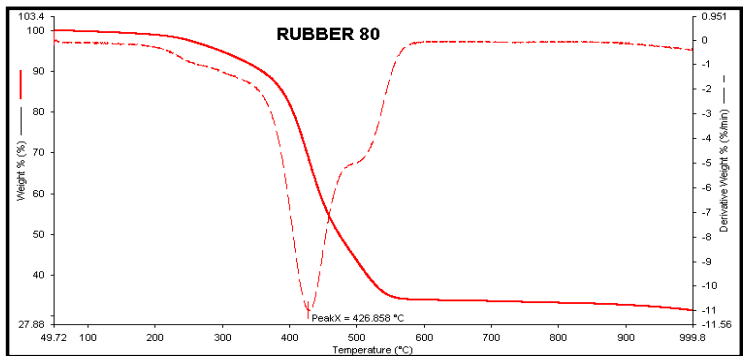

Figure 3: $\quad$ TG/DTG curve of rubber.

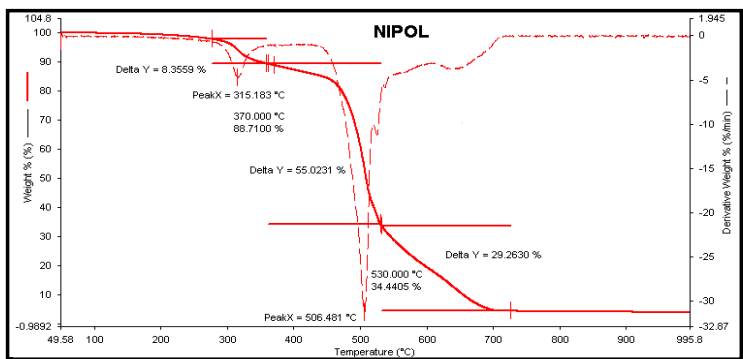

Figure 4: $\quad$ TG/DTG curve of Nipol.

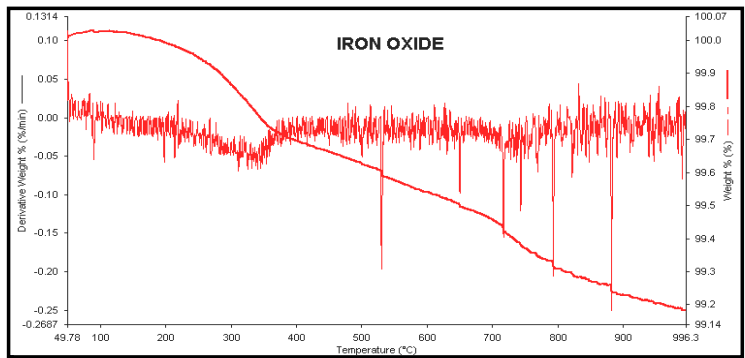

Figure 5: $\quad$ TG/DTG curve of iron oxide. 


\subsection{TG/DTG-MS of brake pad samples}

This section elaborates the TG/DTG-MS results obtained for the five novel brake pad formulations developed by our research group. Discussion of the thermal characteristics of the samples will be based on the results of the five raw materials provided in the preceding section besides the EGA results which evidence the decomposition of the samples with increase in temperature. The temperature range of interest is up to $600^{\circ} \mathrm{C}$ for which calculation of total weight loss and thermal degradation pattern is accounted for in the discussion.

Fig. 6(a) shows the TG/DTG curve of sample SP1 while fig. 6(b) is the mass spectrum for the EGA. This sample decomposes in four steps. The initial weight loss occurred between before $115^{\circ} \mathrm{C}$. Weight loss of $2.27 \%$ was registered at the interval of $230^{\circ} \mathrm{C}$ to $403^{\circ} \mathrm{C}$ (third step) and minimum DTG temperature, $\mathrm{T}_{\mathrm{DTG}}$, min, of $363^{\circ} \mathrm{C}$ but no MS signal was recorded. This suggests that no gaseous product(s) was released in this interval hence possibility of evaporation of the organic compounds is excluded. However, MS signals (refer fig. $6(\mathrm{~b})$ and table 1) were detected in the $4^{\text {th }}$ and $5^{\text {th }}$ weight loss regions $\left(<600^{\circ} \mathrm{C}\right)$ due to probable release of organic and inorganic gases as may be caused by removal of carbon.

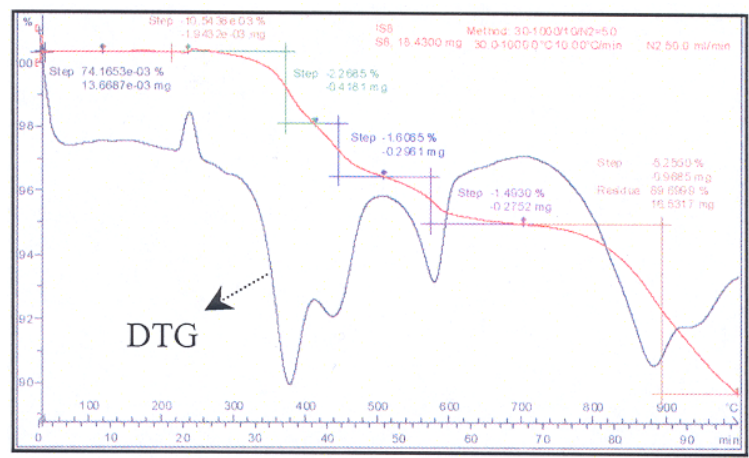

(a)

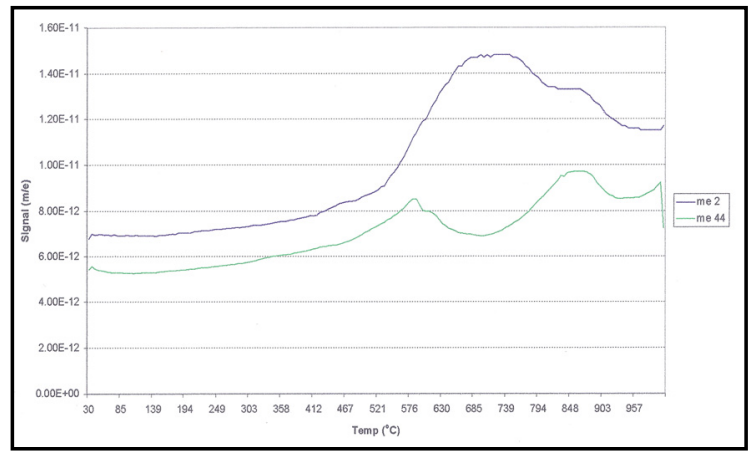

(b)

Figure 6: (a): TG/DTG curve of sample SP1. (b): MS spectrum of sample SP1. 
Table 1: $\quad$ MS results showing the possible molecule release.

\begin{tabular}{|c|c|c|}
\hline Mass number & Key Fragment & Probable molecule \\
\hline 2 & $\mathrm{H} 2+$ & $\mathrm{H}_{2}$ \\
& $\mathrm{He}++$ & $\mathrm{He}$ \\
\hline 44 & $\mathrm{C} 3 \mathrm{H} 8+$ & $\mathrm{C}_{3} \mathrm{H}_{8}$ \\
& $\mathrm{CO} 2+$ & $\mathrm{CO}_{2}$ \\
& $\mathrm{C} 2 \mathrm{H} 4 \mathrm{OH}+$ & $\mathrm{C}_{2} \mathrm{H}_{5} \mathrm{OH}$ \\
\hline
\end{tabular}

Mass number 44 also suggests the possible release of propane and ethanol as may be caused by volatilization of organic compounds due to steam at higher temperature. Oxidation of the carbon content might also be possible. This result substantiates the corresponding weight loss between $403^{\circ} \mathrm{C}-688^{\circ} \mathrm{C}$.

Thermal events of sample SP2 is shown in figs. 7(a) and 7(b). Major weight loss occurred in two significant steps beginning from $402^{\circ} \mathrm{C}$ as in sample SP1 but the total weight loss is slightly higher i.e. $5.48 \%$. MS signal were also detected at these steps with probable molecule as shown in table 1 corresponding to the regions of oxygen inward or the carbon containing species outward.

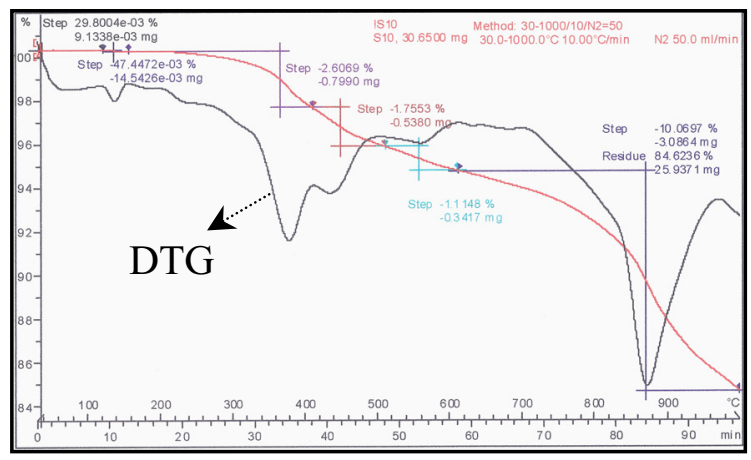

(a)

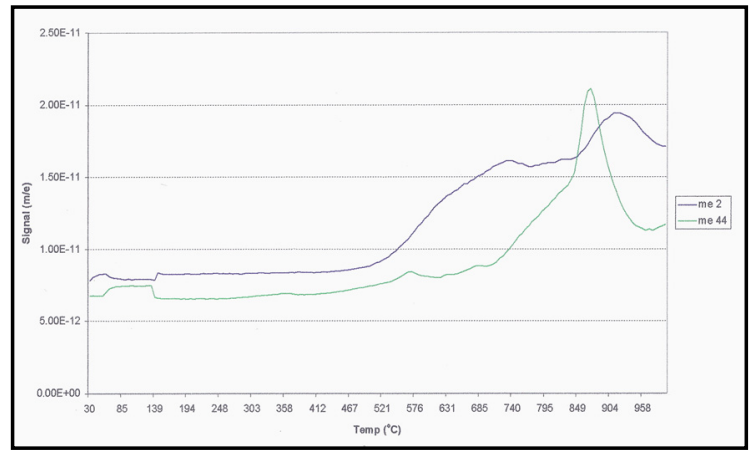

(b)

Figure 7: (a): TG/DTG curve of sample SP2. (b): MS spectrum of sample SP2. 
Figs. 8(a) and 8(b) show the TG/DTG curves and MS spectra for sample SP3, respectively. This sample exhibited a 4-step thermal decomposition with a relatively considerable weight loss of $1.94 \%$ in the interval of $197^{\circ} \mathrm{C}-409^{\circ} \mathrm{C}$. The corresponding $\mathrm{T}_{\mathrm{DTG}}$, min $374^{\circ} \mathrm{C}$, which indicates possible decomposition of the barium element. Two more weight loss steps took place at the DTG temperatures of $439^{\circ} \mathrm{C}$ and $559^{\circ} \mathrm{C}$, with the later emitting $\mathrm{MS}$ signals as in table 1 . Total weight loss up to $559^{\circ} \mathrm{C}$ is $5.71 \%$. It is worth mentioning that a significant weight loss of $4.67 \%$ was recorded at the $654^{\circ} \mathrm{C}-789^{\circ} \mathrm{C}$ temperature zones (probable decomposition of iron oxide) though this is beyond the temperature range of interest.

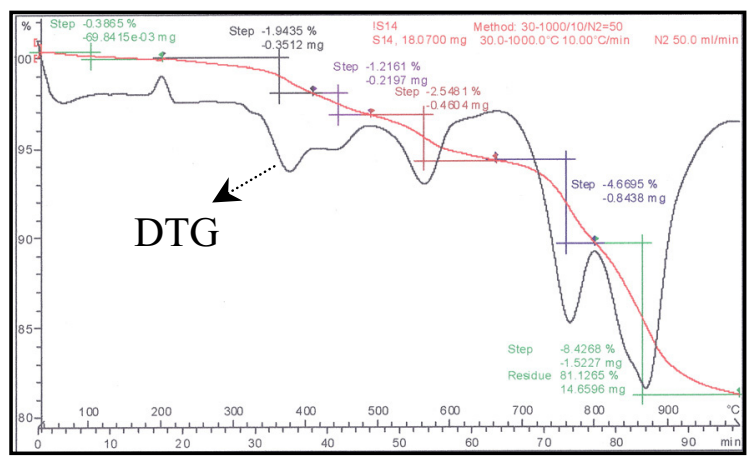

(a)

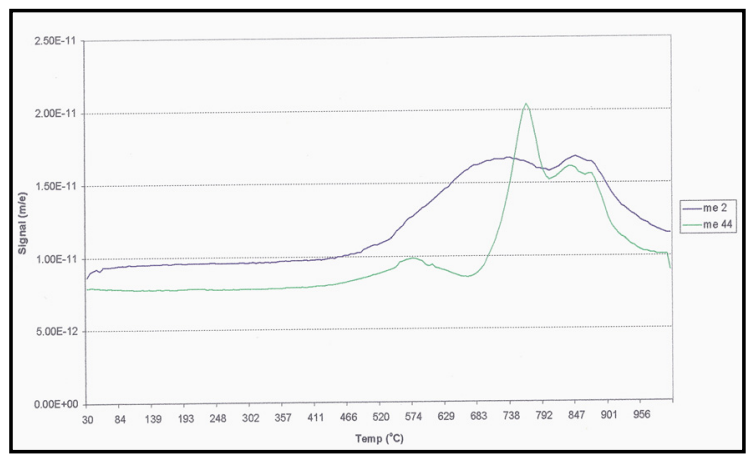

(b)

Figure 8: (a): TG/DTG curve of sample SP3. (b): MS spectrum of sample SP3.

Decomposition of sample SP4 occurred in just three steps as shown in fig. 9(a). Maximum weight loss of $4.14 \%\left(\mathrm{~T}_{\mathrm{DTG}}, \min =378^{\circ} \mathrm{C}\right)$ was registered at a rather broad temperature range of $171^{\circ} \mathrm{C}-488^{\circ} \mathrm{C}$. The mass to charge ratio of 
ionised fragments as shown in fig. 9(b) reveals that gaseous products with molecular mass as in table 1 were released at around $554^{\circ} \mathrm{C}$. A weight loss of $1.63 \%$ was detected at this temperature zone. Referring to the preceding section, this result indicates the oxidation and/or evaporation of Nipol and barium. The total weight loss at the temperature zone of interest is $5.77 \%$.

Figs. 10(a) and 10(b) are the TG/DTG curves and MS spectra for sample SP5, respectively. The thermogravimetric results show that sample S20 decomposes in four steps up to $653^{\circ} \mathrm{C}$. The first two steps produced small reduction in weight totalling $1.2 \%$. Substantial weight loss of $3.58 \%$ occurred at $\mathrm{T}_{\mathrm{DTG}}$, $\min =378^{\circ} \mathrm{C}$ with discharge of gases as in table 1. This observation is similar to that of sample SP4 but the weight decrease of sample SP5 is lesser by $0.56 \%$, hence an improvement in the formulation. Sample SP5 also registered the lowest total weight loss of $5.30 \%$ among all the five samples.

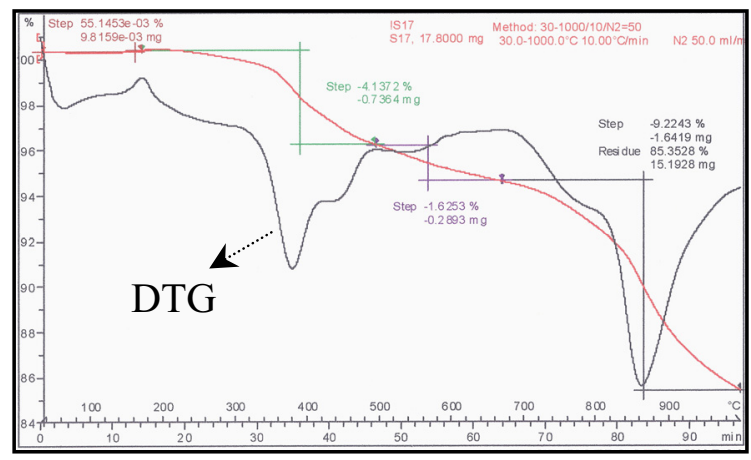

(a)

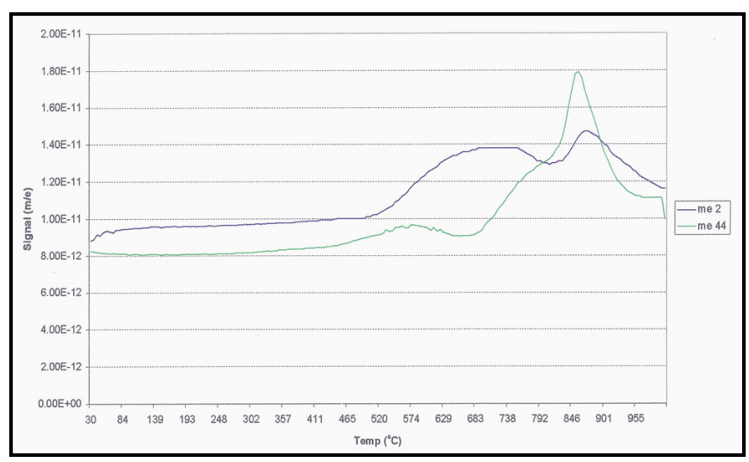

(b)

Figure 9: (a): TG/DTG curve of sample SP4. (b): MS spectrum of sample SP4. 


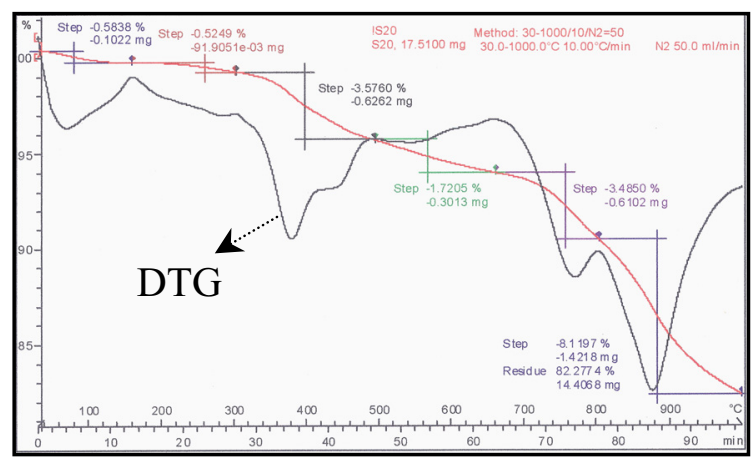

(a)

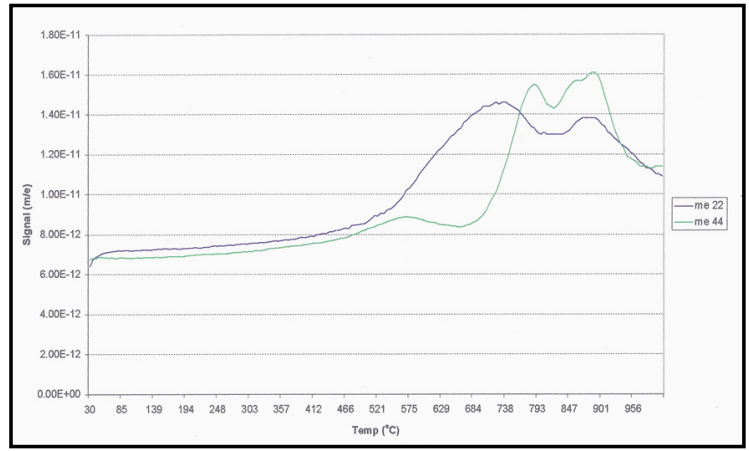

(b)

Figure 10: (a): TG/DTG curve of sample SP5. (b): MS spectrum of sample SP5.

\section{Summary}

TG/DTG-MS combined analysis was conducted on five new brake pad formulations. MS results indicated evolution of gases during the temperature ramp especially after $400^{\circ} \mathrm{C}$ and were related to the physical-chemical reaction of the raw ingredients. Based on the results of TG/DTG, it was found that sample SP1 and SP5 are the favourable samples with the reference to the commercial brake pad. Sample SP1 exhibits a controlled rate of decomposition apparently over a wider temperature range $\left(230^{\circ} \mathrm{C}-688^{\circ} \mathrm{C}\right)$ with a total loss of weight of $5.37 \%$. In contrast, sample SP5 decomposed in a greater magnitude in a single step and narrower temperature gap $\left(303^{\circ} \mathrm{C}-483^{\circ} \mathrm{C}\right)$ albeit the total weight reduction is $5.30 \%$. However, both of these measurements are still high compared to that of commercial brake pad (4.79\%) and further refinement to the compositional aspects of the formulations will be undertaken to achieve a stable thermal decomposition and reduced weight loss comparable to the commercially available brake pad. 


\section{Acknowledgements}

This work is supported by MOSTI Malaysia through IRPA Grant 03-02-010055-PR0066/04-03. The authors would like to thank Dr. Mohmad Soib bin Selamat (AMREC, SIRIM), Dr. Talib Ria Jaafar (AMREC, SIRIM) and Dr. Mustafar Sudin (UTP, Tronoh) for their valuable support and useful discussion. Dr. Vengadeswaran and staff members of the Combinatorial Technologies and Catalysts Research Centre (COMBICAT) of University Malaya are thanked for their technical assistance and useful discussions. The administrative support provided by the Faculty of Mechanical Engineering, UiTM and the Institute of Research, Development and Commercialisation, UiTM is appreciated.

\section{References}

[1] Lu, Y., Tang, C.F., \& Wright, M.A., Optimization of a commercial brake pad formulation. J. Applied Polymer Science, 84 (13), pp. 2498 - 2504, 2002.

[2] Samyn, P., Schoukens, G., Quintelier, J. \& De Baets, P., Friction, wear and material transfer of sintered polyimides sliding against various steel and diamond-like carbon coated surfaces. Tribology International, 39, pp. $575-589,2006$.

[3] Ingo, G.M., Uffizi, M.D., Falso, G., Bultrini \& Padeletti, G., Thermal and microchemical investigation of automotive brake pad wear residues. Thermochimica Acta, 418, pp. 61 - 68, 2004.

[4] Jang, H., Lee, J.S. \& Fash, J.W., Compositional effects of the brake friction material on creep groan phenomena. Wear, 251, pp. 1477-1483, 2001.

[5] Mackin, T.J. et al., Thermal cracking in disc brakes. Engineering Failure Analysis, 9, pp. 63 - 76, 2002.

[6] Cueva, G., Sinatora, A., Guesser, W.L. \& Tschiptschin, A.P., Wear resistance of cast irons used in brake disc rotors. Wear, 255, pp. $1256-$ 1260, 2003.

[7] Mutlu, I., Eldogan, O. \& Findik, F., Tribological properties of some phenolic composites suggested for automotive brakes. Tribology International, 39, pp. 317 - 325, 2006.

[8] Kamruddin, M., Ajikumar, P.K., Dash, S., Tyagi, A.K. \& Raj, B., Thermogravimetry-evolved gas analysis-mass spectroscopy system for materials research. Bulletin of Materials Science, 26 (4), pp. 449 - 460, 2003.

[9] Basalik, T., TGA with evolved gas analysis. American Laboratory, pp. 24 $-27,2005$.

[10] Zhang, X., Li, Y., Lv, G., Zuo, Y. \& Mu, Y., Thermal and crystallization studies of nano-hydroxyapatite reinforced polyamide 66 biocomposites. Polymer Degradation and Stability, 91, pp. 1202 - 1207, 2006.

[11] Chiang, I.W. et al., Purification and Characterization of Single-Wall Carbon Nanotubes (SWNTs) Obtained from the Gas-Phase Decomposition of CO (HiPco Process). J. Phys. Chem. B., 105, pp. $8297-$ 8301, 2001. 